\title{
TERIA F. CHOPIN SOFRIDO DE FIBROSE CÍSTICA? REVISÃO HISTÓRICA
}

\section{DID F. CHOPIN HAVE CYSTIC FIBROSIS? HISTORICAL REVIEW}

DOI: $10.5380 /$ rmu.v2i1.40673

Matheus Kahakura Franco Pedro ${ }^{1}$

\section{RESUMO}

Introdução: o compositor polonês Fréderic Chopin (1810-1849) sofreu toda vida com uma afecção pulmonar, na época diagnoticada tuberculose; fibrose cística é um diagnóstico provável. Objetivo e Métodos: descrever a doença de Chopin como relato de caso. Revisados 5 artigos sobre sua doença, em inglês, na base de dados PubMed. Resultados: desde a infância Chopin sofreu de diarréia recorrente, perda de peso, dispnéia e infecções respiratórias. Em 1838 desenvolveu tosse, febre e hemoptise. O diagnóstico foi tuberculose, nunca confirmado pela sua ausculta pulmonar; ainda, nenhum contato de Chopin adquiriu a doença. Nos próximos anos, teve tosse produtiva, dispnéia progressiva e cianose. Em 1849 sofreu três dias com tosse intensa e dispnéia ao repouso, falecendo em 17/10. À autópsia, cardiomegalia foi a única alteração descrita (possível cor pulmonale). Sua história familiar e esterilidade também sugerem fibrose cística. Conclusão: a doença de Chopin fez parte das tragédias que o inspiraram; embora os médicos da época tenham diagnosticado tuberculose, o conhecimento médico atual permite desenvolver outras hipóteses, sendo a fibrose cística extremamente plausível.

Palavras-chave: fibrose cística, tuberculose, Chopin

\section{ABSTRACT}

Introduction: the Pole Frédéric Chopin (1810-1849) suffered his entire live from pulmonary disease, diagnosed at the time as tuberculosis; cystic fibrosis is a likely diagnosis. Objetive and Methods: to describe Chopin's illness as a case report. Five articles about his disease, in English, were revised in the PubMed database. Results: since his childhood Chopin suffered from recurrent diarrhea, weight loss, dyspnea and respiratory infections. In 1838 he developed cough, fever and hemoptysis. The diagnosis was tuberculosis, even without changes in his thoracic auscultation; moreover, no acquaintance of Chopin contracted the disease. In the following years, he had productive cough, progressive dyspnea and cyanosis. In 1849 he had a three day bout of intense coughing and rest dyspnea, dying on the 17th of October. In his autopsy, cardiomegaly was the only visible alteration (possible cor pulmonale). His familiar history and infertility also suggest cystic fibrosis. Conclusion: Chopin's disease was part of the tragedies that inspired him; although contemporary physicians had diagnosed tuberculosis, the medical knowledge of our days allows the development of other hypothesis, with cystic fibrosis being a strong contender.

Key words: cystic fibrosis, tuberculosis, Chopin

\author{
1-Universidade Federal do Paraná \\ Contato do Autor / Mail to: \\ Matheus Kahakura Franco Pedro - matheuskfpedro@hotmail.com \\ Rua Coronel João Guilherme Guimarães, 1008-3, Bom Retiro, Curitiba, Paraná, 80520-280
}




\section{INTRODUÇÃO}

O polonês Fréderic Chopin (1810-1849) foi a epítome do compositor romântico (figura 1): foi exilado por uma revolução, viveu turbulentamente com sua amante e sofreu de uma doença pulmonar intratável; mesmo assim, produziu uma vasta obra para piano que revolucionou as possibilidades do instrumento, tanto em termos técnicos quanto em lirismo. Seus prelúdios, estudos, mazurcas, noturnos e polonaises são ainda hoje a base do repertório pianístico. Sua vida, no entanto, foi marcada pela doença: embora os médicos da época tenham diagnosticado tuberculose, autores modernos atribuem seus sintomas a outras patologias descobertas posteriormente pela ciência médica, como fibrose cística.

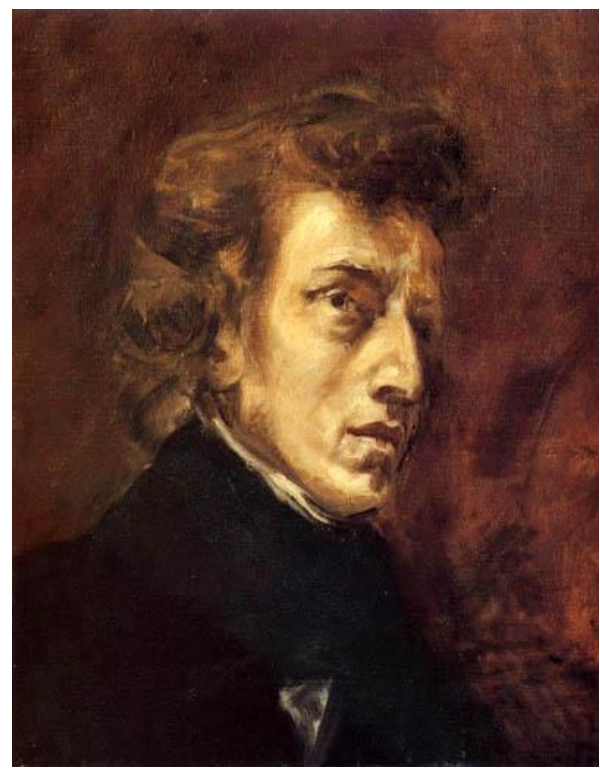

Figura 1 - Frédéric Chopin, retratado por Eugène Delacroix,1838.

Fonte:http://upload.wikimedia.org/wikipedia/common s/f/f5/Eug\%C3\%A8ne_Ferdinand_Victor_Delacroix_043 .jpg (acessado em 02/12/2014)

\section{MÉTODOS}

Descrever a doença de Chopin como relato de caso histórico, traçando sua patografia, com o objetivo de discutir a hipótese diagnóstica de fibrose cística, revisando a patologia e sua probabilidade no quadro clínico. Foram revisados 5 artigos sobre a doença de Chopin, todos em inglês, através da base de dados PubMed. Apesar da impossibilidade da descrição fiel da história mórbida nos moldes da Semiologia, dado o desfecho da doença e sua narração a posteriori, utilizaremos esquema derivado do adotado pelas disciplinas de Propedêutica Médica e Semiologia da
Faculdade de Medicina da Universidade Federal do Paraná.

\section{RELATO DO CASO}

Revisão da patologia: dentre as doenças autossômicas recessivas ameaçadoras à vida, a fibrose cística é a mais comum em populações caucasianas, acometendo 1 a cada 2000 a 3000 nascidos vivos ${ }^{1}$. A fibrose cística (mucoviscidose), descrita em 1932, é uma doença hereditária ligada ao cromossomo 7 causada por disfunção em um canal de cloro (canal regulador transmembrana da fibrose cística). Nessa patologia, uma mutação diminui o fluxo de cloro, aumentando a viscosidade do muco e facilitando a colonização por patógenos, como bactérias do genêro Pseudomonas. A fibrose cística clássica, mais severa, é caracterizada por disfunções em múltiplos sistemas (pâncreas, tratos respiratório e reprodutivo masculino) e cloro elevado em teste de suor (acima ou igual a 60 $\mathrm{mmol} / \mathrm{L}$ ). A variante não-clássica inclui pacientes com as manifestações clínicas porém sem alterações significativas no teste do suor e pacientes com manifestações clínicas menos acentuadas, que permitem sobrevida maior do paciente, ocorrendo em $2 \%$ dos $\operatorname{casos}^{2,3}$.

História Mórbida Atual: Chopin viajou com sua amante, George Sand, para a ilha de Mallorca em 1838, fugindo do úmido inverno parisiense. No entanto, lá ele desenvolveu tosse, febre e hemoptise. Sand buscou auxílio médico; os três clínicos que o atenderam diagnosticaram tuberculose, devido à hemoptise e ao esputo com estrias sanguinolentas. Enquanto em Paris tuberculose era considerada doença hereditária, na Espanha era considerada uma infecção. O casal tornou-se temido na ilha, com a população os evitando e o hospedeiro os forçando a comprar toda a mobília de seu quarto e depois queimar. Ao retornarem a Paris, Chopin foi auscultado por especialistas, que não detectaram alterações audíveis para reforçar o diagnóstico de tuberculose. Ainda contra a tuberculose fala o fato de que nenhum contato de Chopin, em nenhum momento de sua história mórbida pertinente, adquiriu a doença ${ }^{4}$.

História Mórbida Pregressa: não há segurança sobre a data de nascimento de Chopin; de acordo com seu pai pode ter sido 22 de fevereiro ou 1 o de março de 1810, em Zelazowa Wola. Desde a infância Chopin, conforme registrado em descrições de terceiros e suas próprias cartas, sofreu de diarréia recorrente, dificuldade de ganho de peso, dispnéia e infecções respiratórias frequentes. Dos 15 anos até a morte, nunca esteve por mais do que poucos meses sem tosse ou outros sintomas respiratórios. Aos 16, sofreu continuamente por 6 meses de sintomas respiratórios, 
o que quase lhe custou a vida ${ }^{5}$. Aos vinte anos saiu da Polônia em meio à instabilidade política, tendo se mudado para Paris. Seus sintomas de hemoptise, febre e tosse produtiva persistiram, com infecções de repetição. Similarmente, sintomas de puberdade tardia se fizeram presentes, como atraso no crescimento de fâneros.

História Mórbida Familiar: sua história familiar é sugestiva de fibrose cística: enquanto o pai de Chopin, Nicola, sofreu de uma doença pulmonar não especificada, sua irmã mais nova, Emilia, foi uma criança que sofreu do tosse crônica, perda ponderal, dispnéia e hematêmese; aos 14 anos, faleceu de hemorragia digestiva alta. Outra irmã, Ludovika, faleceu aos 47 anos de uma doença pulmonar não identificada.

Perfil Psicossocial: Chopin procurou evitar a vida estressante de um pianista de concerto; embora tivesse treinado para isso, não resistia aos rigores de um concerto virtuoso longo. Seu estado consumptivo o forçou a exibir sua técnica no ambiente mais íntimo e aristocrático dos círculos da elite parisiense. Passou a dar aulas, porém sempre em decúbito. O compositor nunca teve filhos, apesar de 11 anos de relacionamento com Sand, que teve dois filhos em seu primeiro casamento; esterilidade é parte do quadro de fibrose cística.

Condições e Hábitos de Vida: Sua alimentação tornou-se errática; devido à disfunção pancreática, era necessária busca rigorosa por alimentos que ele aceitasse; uma dieta equivocada, gordurosa, causava dor abdominal e diarréia ${ }^{6}$. Chopin evitava exercício, mesmo que esse fizesse parte do tratamento recomendado pelos tísicos contemporâneos; mesmo subir uma escada lhe causava dispnéia intensa

Exame físico: em 1840, apesar de sua altura de 1,70, Chopin pesava $45 \mathrm{~kg}$. Relatos da época falam de seu tórax "em forma de barril". Seus membros foram descritos como anormalmente finos; suas mãos estavam sempre cobertas por luvas, menos por dandismo e sim por vergonha. Contrariando as convenções estilísticas da pintura da época para pianista, Chopin não era retratado com as mãos ao piano, as escondendo.

Desfecho: após se separar de George Sand em 1847, a saúde de Chopin decaiu rapidamente; um viagem à Escócia no inverno em 1848 causou nova exacerbação de seus sintomas respiratórios. Em 1849, sob os cuidados de sua irmã Ludovika, foi atendido por Cruveilhier, o mais eminente tisiologista parisiense da época, que o tratou com dietas e repouso. Em julho, sua perda ponderal e caquexia atingiram um ponto máximo, associadas a dores articulares em tornozelos, impedindo sua deambulação, e congestão e cianose faciais. Em outubro, seu quadro respiratório acentuouse novamente. Após três dias com dispnéia aos mínimos esforços e tosse intensa, refratária ao tratamento padrão da época com ópio, Chopin faleceu em 11 de outubro de 1849, consciente até os últimos minutos, sem desorientação, hipertonia ou disfagia. Em sua certidão de óbito consta "tuberculose pulmonar e laríngea" como causa da morte, com cardiomegalia sendo a única alteração descrita em sua autópsia; esta pode ser cor pulmonale causado pela fibrose cística e bronquiectasia, com lesões mais sutis à macroscopia; em caso de tuberculose, espera-se lesões pulmonares cavitantes maciças a ponto de causar insuficiência cardíaca, bem como compatíveis com uma vida de sintomas. Cruveilhier escreveu que nunca havia visto doença como a de Chopin.

Enquanto seu corpo foi sepultado no cemitério Père Lachaise, em Paris, seu coração retornou à Polônia, encontrando-se na igreja do Sagrado Coração, em Varsóvia.

\section{DISCUSSÃO}

O único diagnóstico plausível para a medicina do século XIX foi tuberculose, apesar de todas as incoerências da hipótese com a clínica. Uma doença genética pode ser facilmente aventada, tendo em vista que duas de suas três irmãs e pai sofreram de doença pulmonar similar, causando a morte prematura de ambas, bem como o caráter sistêmico e progressivo da doença que acometeu Chopin e suas irmãs.

Fibrose cística e deficiência congênita de $\alpha 1$ antitripsina são hipóteses plausíveis, já tendo sido defendidas por $\mathrm{O}^{\prime}$ Shea ${ }^{6}$ e Kuzemko ${ }^{7}$. A deficiência congênita da enzima $\alpha 1$-antitripsina é uma hipótese menos provável tendo em vista a diarréia crônica de Chopin, compatível com insuficiência pancreática, e ausência de icterícia e ascite ${ }^{8}$, tanto em Chopin quanto para o caso do sangramento esofageano de Emilia ter sido causado por hipertensão portal.

Outras hipóteses descritas na literatura incluem bronquiectasia, hipogamaglobulinemia, estenose mitral, aspergilose broncopulmonar alérgica, incompetência tricúspide, síndrome de Churge-Strauss, hemosiderose pulmonar e malformação arterovenosa pulmonar $^{8}$. No entanto, essas hipótes não se adequam à clínica descrita, sendo menos prováveis.

Assim, fibrose cística torna-se um diagnóstico provável, conforme demonstrado na tabela 1 .

\section{CONCLUSÃO}

A doença de Chopin fez parte das tragédias que inspiraram sua música; embora os médicos da época tenham diagnosticado tuberculose, o conhecimento médico atual permite desenvolver hipóteses mais prováveis, sendo a fibrose cística uma candidata forte. O exemplo de um caso histórico de uma doença torna-se exemplo para médicos e 


\section{REVISTA MÉDICA DA UFPR}

estudantes, ampliando a percepção da dimensão da doença e permitindo seu reconhecimento na prática clínica, e torna-se exemplo para o paciente com a doença, tendo em vista as diferenças do tratamento da época e sua evolução até os dias de hoje.

Quadro 1 - Sumário da clínica e história de Chopin, adaptado de Kubba e Young ${ }^{5}$

\begin{tabular}{|l|}
\hline História familiar \\
Duas irmãs com sintomas similares e morte \\
prematura \\
\hline Sintomas \\
\hline Tosse produtiva, hemoptise, dispnéia desde a \\
infância. \\
Diarréia, intolerância a alimentos gordurosos, \\
hematêmese. \\
Intolerância ao esforço, fatiga, dificuldade em \\
obter ganho ponderal. \\
Infertilidade. \\
\hline Sinais \\
\hline "Tórax em barril" \\
Peso: 48 kg \\
Altura: 1,70 m \\
Membros esquálidos \\
Cianose \\
\hline
\end{tabular}

\section{REFERÊNCIAS}

1. Cystic Fibrosis Foundation Patient Registry. Annual data report 2011. [Internet] [Acesso em 2014 Dez 01]. Disponível em: http://www.cff.org/UploadedFiles/ research/ClinicalResearch/2011-Patient-Registry.pdf

2. Boyle MP. Nonclassic cystic fibrosis and CFTR-related diseases. Curr Opin Pulm Med. 2003;9(6): 498-503.

3. De Boeck K, Wilschanski M, Castellani C, Taylor C, Cuppens $\mathrm{H}$, Dodge J et al. Diagnostic Working Group Cystic fibrosis: terminology and diagnostic algorithms. Thorax. 2006;61(7): 627-635.

4. Rietschel ET, Rietschel M, Beutler B. How the mighty have fallen: fatal infectious diseases of divine composers. Infect Dis Clin N Am. 2004;18: 311-339

5. Kubba AK, Young M. The long suffering of Frederic Chopin. Chest. 1998(136): 210-216.

6. O'Shea JG. Was Frédéric Chopin's illness actually cystic fibrosis? Med J Aust. 1987;147: 586-589.

7. Kuzemko J. Chopin's illness. J Royal Soc Med. 1994;87: 769-772.

8. Majka L, Gozdzik J, Witt M. Cystic fibrosis - a probable cause of Frédéric Chopin's suffering and death. J Appl Genet. 2003;44(1): 77-84 